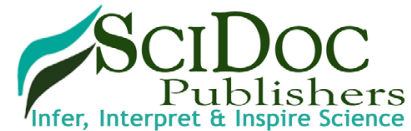

International Journal of HIV/AIDS and Research (IJHR)

ISSN 2379-1586

\title{
Behavioral Competencies and Low Alcohol and Drugs Use Predicts Medication - Adherence Behaviors Among HIV+ Persons from Venezuela
}

Research Article

\author{
JA Piña ${ }^{1 *}$, M Miaja $^{2}$, EM Álvarez 3 , RD González ${ }^{3}$ LE Fierros ${ }^{4}, J^{2}$ Ybarra ${ }^{5}$ \\ ${ }^{1}$ Institutional Health Program, University of Sonora, Mexico. \\ 2 Hospital "Zambrano Hellion”, Technological Institute of Monterrey, Mexico. \\ ${ }^{3}$ Program of Psychology, Cent Occidental University "Lisandro Alvarado", Lara, Venezuela. \\ ${ }^{4}$ Program of Psychology, University of Sonora, Mexico. \\ ${ }^{5}$ Unit of Social Work and Sciences for Human Development, Autonomous University of Tamaulipas, Mexico.
}

\section{Abstract}

Background: Treatment success among HIV+ persons under an antiretroviral regimen strongly rely on individual factors. Objective: To test the variables of a psychological model and the influence of alcohol and drugs use in the prediction of medication-adherence behaviors.

Methods: We conducted a cross-sectional study of $124 \mathrm{HIV}+$ persons recruited in an outpatient clinic in the state of Lara, Venezuela, who completed a self-administered questionnaire measuring psychological variables and medication-adherence behaviors, as well as an index of alcohol and drugs use. Moment-product correlation and structural equation modeling were applied for data analyses.

Results: Current behavioral competencies showed a direct effect on medication-adherence behaviors, mediating the indirect effect of low alcohol and drugs use. The structural equation modeling demonstrated a good fit to the sample data: $\chi^{2} /$ $\mathrm{gl}=1.42, \mathrm{GFI}=0.99, \mathrm{AGFI}=0.94, \mathrm{NFI}=0.98, \mathrm{CFI}=0.99, \mathrm{FD}=0.02[\mathrm{FDMI}=1.13], \mathrm{PNCP}=0.01[\mathrm{PNCPMI}=1.08]$, RMSEA $=0.05$, RMSSR $=0.04$.

Conclusion: Behavioral competencies and low alcohol and drugs use were significant predictors of medication-adherence behaviors. Further research direction, including national wide of HIV+ persons from Venezuela and the development of interdisciplinary interventions that promote and sustain medication-adherence behaviors are discussed.

Keywords: Behavioral Competencies; Alcohol; Drugs; Adherence Behaviors; HIV+ Persons; Venezuela.

\section{Background}

The success of the antiretroviral therapy (ART) among HIV+ persons strongly rely on individual factors, including the patient's personality characteristics $[1,2]$, a good motivation and a set of knowledge, skills and abilities related to both the disease and treatment [3], the concurrence of adaptative emotional states [4], and a low alcohol and drugs use [5, 6]. Despite convergent body of evidence has confirmed the role of individual factors on medication-adherence behaviors in Latin America countries and the Caribbean region, such as Argentina [7], Chile [8], Peru [9] and the Dominican Republic [10], little progress has been made in countries like Venezuela. In fact, only two studies using $\mathrm{HIV}+$ samples have been found, in both cases putting emphasis in the influence of socio-demographic and clinical patient's characteristics on medication-adherence behaviors [11, 12].

Considering those antecedents and the need to investigate the influence of individual factors on medication-adherence behaviors in Venezuelan HIV+ persons, this study was justified in a psychological model for the research of adherence behaviors (PMAB) in persons living with chronic diseases, including HIV infection [13]. As show in Figure 1, the model emphasizes the interaction of psychological and biological variables along four phases. The first involves psychological process variables related to personality, motives and behavioral competencies; the second involves the HIV diagnosis and other co-morbidities; the third involves two types of behaviors: medication-adherence behaviors and disease-related behaviors - e.g., impulsivity, anger, depression, social isolation, etc.; the fourth involves biological measures and

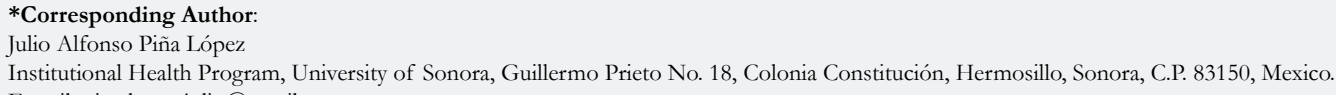

Citation: JA Piña, M Miaja, EM Álvarez, RD González, LE Fierros, JL Ybarra (2016) Behavioral Competencies and Low Alcohol and Drugs Use Predicts Medication - Adherence Behaviors Among HIV+ Persons from Venezuela. Int J AIDS Res. 3(5), 73-77. doi: http://dx.doi.org/10.19070/2379-1586-1600016

Copyright: JA Piña ${ }^{\circ}$ 2016. This is an open-access article distributed under the terms of the Creative Commons Attribution License, which permits unrestricted use, distribution and reproduction in any medium, provided the original author and source are credited. 
Figure 1. Psychological model for the research of medication-adherence behaviors (PVAB).

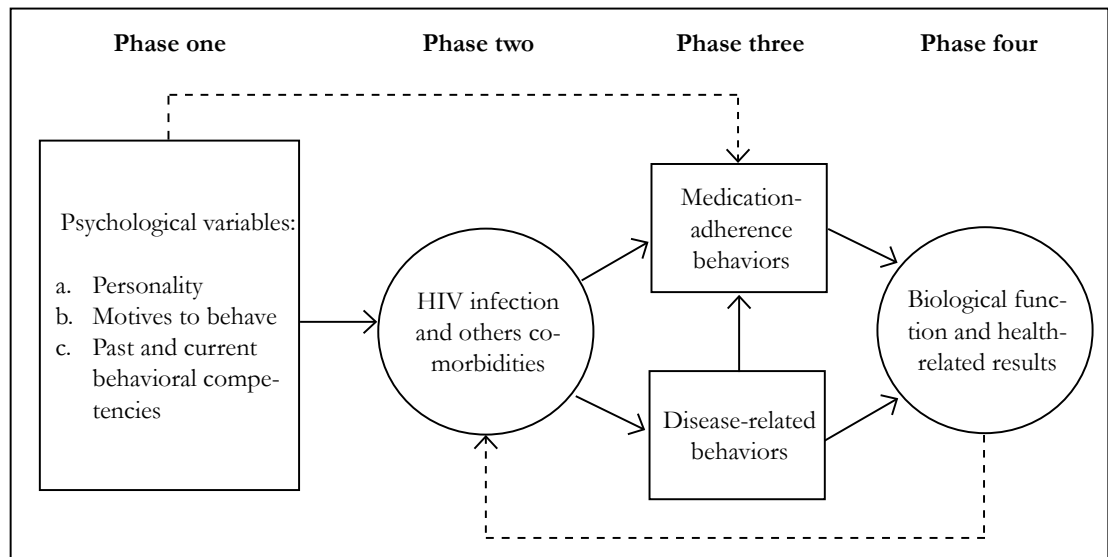

health results. Studies recently carried out with different samples in Mexico demonstrate the conceptual and empirical support of the PMAB [14-16].

Base on the psychological model for adherence behaviors and an index of substances use, the main purpose of this study was to identify the variables predicting medication-adherence behaviors among HIV+ patients from Venezuela. In this study we hypothesized that: a) past behavioral competencies would play a major role on current behavioral competencies; b) motives and current behavioral competencies would directly and significantly predict medication-adherence behaviors; c) alcohol and/or drugs use would indirectly and significantly predict medicationadherence behaviors, mediated by the influence of both, current behavioral competencies and motives.

\section{Methods}

\section{Participants and Procedure}

Participants in this cross-sectional study were recruited from an outpatient clinic, located in the state of Lara, Venezuela. Participants were randomly selected from those who were present at the clinic between January and February 2015; around 20\% of $\mathrm{HIV}+$ patients under an ART regimen were included in the study. Inclusion criteria were as follow: 1) To have at least 18 years of age; 2) Being under an ART regimen; 3) Having no psychological problems or cognitive deficit limiting the understanding of instructions and/or questions. Participants were exposed to the objective of the study and those who accepted to cooperate voluntarily were asked to read and sign an informed consent form. Once the informed consent form and the questionnaire were completed, both were putted in sealed envelope. The study was approved by the Research Program of Psychology of the Cent Occidental University "Lisandro Alvarado" and by the National Program on AIDS (PRONASIDA), both in the state of Lara, Venezuela.

\section{Study measures}

Participants answered to a self-administered instrument, originally designed and validated in Mexico [17], which was recently adapted and validated in Venezuela, in which a three-factor structure was created, explaining $52.3 \%$ of the total variance [18]. Past behavioral competencies included questions regarding what the patient did or not in relation to any disease before the HIV diagnosis: if you get sick (e.g., flu or stomach), did you take your medications as prescribed by your physician? Responses to each question were assigned a score from 1 (never) to 4 (always). Current behavioral competencies included questions regarding ART medication and treatment care: can you tell us how often follow the instructions of your physician about your health care? Responses to each question were assigned a score from 1 (never) to 4 (always). Motives to behave included questions regarding the reasons underlying the medication consumption: I take my medication because that keep me healthy as long as possible. Response to each question were assigned a score from 1 (Is not a strong motive) to 4 (Is a strong motive).

Medication-adherence behaviors were measured using a simple question about the frequency with which $\mathrm{HIV}+$ persons take their medication: In the last month, how frequency did you take your medication as prescribed? Responses to this question were assigned a score from 1 (I never take my medication) to 5 (I take my medication all days of the month). Also, we added an index that contains two questions related with alcohol and drugs use in the course of the last month.

\section{Statistical analyses}

Associations between variables were calculated by the productmoment Pearson ( $r$ ) correlation. With the structural equation modeling we tested the direct/indirect effects of behavioral competencies, motives and alcohol and/or drugs use on medication-adherence behaviors; several indexes for interpreting data adjustment were considered according to recommendations $[19,20]$ :

1. Basic indexes included the chi-squared test $\left(\chi^{2}\right)$, the quotient of the chi-squared test divided into the degrees of freedom $\left(\chi^{2} / d f\right)$, and the discrepancy function (DF).

2. Two noncentrality populations indexes included the no centrality-based population parameter (NCPP) and the Root Mean Square Error of Approximation (RMSEA) of SteigerLind.

3. Four comparative indexes included goodness-of-fit index (GFI) of Jöreskog and Sörbom, the GFI adjusted for degrees of freedom (AGFI), the normed fit index (NFI), and the comparative fit index (CFI). Good fit values for the indexes were as follow: $\mathrm{p}$ of $\chi^{2}>0.05 ; \chi^{2} / \mathrm{gl}<2$; DF and NCPP $\leq$ 
$1 / 4$ of the respective value to the independent model; GFI $\geq$ 0.95; AGFI, NFI and CFI $\geq 0.90$; RMSEA $<0.05$.

\section{Results}

As can be seen in Table 1, the average age of the participants was 39.7 ( $\mathrm{SD}=11.0$ ). Is important to notice that most of them were men $(n=91 ; 73.4 \%)$, single $(n=97 ; 78.2 \%)$, with middle education or even professionals $(n=112 ; 90.3 \%)$ and with a stable work position ( $n=86 ; 69.4 \%)$. The participants were living with HIV an average of 77.1 months $(\mathrm{SD}=71.6)$, that is to say from the moment of the seropositivity diagnosis to the current study.

From the total of $\mathrm{HIV}+$ participants in this study, the average response (range from 1 to 5) for the medication-adherence behaviors was 4.9, which represents an optimal adherence percentage of $\geq 95 \%$. Likewise, an elevated average response was found in the past behavioral competencies (17.1 in a range from 4 to 20), current behavioral competencies (22.1 in a range from 5 to 25 ) and motives to behave (14.6 in a range from 4 to 16). Meanwhile, the average of alcohol and drugs use obtained was 1.34 and 1.55, respectively (both with a range from 1 to 5). As a consequence, we can say in general terms that we worked with a sample highly adherent and with good levels in competencies performance and motivation to behave, just as a low alcohol and drugs uses.

In the Table 2, it summarized the results of the bivariate analysis (Pearson's Moment-Product correlations). In the matrix of correlation it can be appreciated that the behavioral competencies factor correlated positively with the frequency of the medicationadherence behaviors, but negatively with the use of alcohol and drugs; at the same time, both of them correlated positively. Therefore, the current behavioral competencies were related with best medication-adherence behaviors, as well as with a low alcohol and drugs use.
With the structural equation modeling, there was made a first analysis contrasting the hypothetical model by ML to evaluate the explained variance and the adjusting of model to the data. By contrasting the hypothetical model, the direct effect of the past behavioral competencies $(\beta=0.04, p=0.63)$ and motives $(\beta=$ $0.05, p=0.59)$ related to the current behavioral competencies was not significant. At the same time the direct effect of motives $(\beta$ $=0.04, p=0.65)$, alcohol use $(\beta=-0.06, p=0.61)$ and drugs use $(\beta=0.20, p=0.08)$ on medication-adherence behaviors was not significant either; therefore, it was evaluated the alternative model, setting to zero accordingly with parameters. The alternative model was fixed on the basis of the correlations and the modification index suggested by the program. As show in Figure 2, the use of alcohol $(\beta=-0.34, p<0.01)$ and drugs $(\beta=-0.37, p<0.01)$ had a direct effect on current behavioral competencies. Also, current behavioral competencies influenced directly on medicationadherence behaviors $(\beta=0.19, p=0.04)$. The alcohol use correlated significantly with a positive sign with the drugs use. The good fit adjustment was maintained by the chi-squared test from the estimate of the discrepancy function by $\mathrm{ML}\left(\chi^{2}[2, \mathrm{~N}=124]\right.$ $=2.85, p=0.24)$. The indexes of goodness from the adjustment were good: $\chi^{2} / \mathrm{gl}=1.42$, GFI $=0.99$, AGFI $=0.94$, NFI $=0.98$, $\mathrm{CFI}=0.99, \mathrm{FD}=0.02[\mathrm{FDMI}=1.13], \mathrm{PNCP}=0.01[\mathrm{PNCPMI}$ $=1.08]$, RMSEA $=0.05$, RMSSR $=0.04$. The model explained $41 \%$ of the variance of current behavioral competencies that, was predicted for low alcohol and drugs use; also, the model explained the $3 \%$ of the variance of the medication-adherence behaviors, which were predicted by an improved current competencies performance.

\section{Discussion}

In this cross-sectional study $124 \mathrm{HIV}+$ persons from the state of Lara, Venezuela were assessed. It was found a practice of the medication-adherence behaviors to ART in high percentage of $\geq 95 \%$ for the sample, highlighting a good performance of the

Table 1. Socio-demographic characteristics of participants $(n=124)$.

\begin{tabular}{|c|c|c|c|c|c|}
\hline Variables & $\mathbf{M}$ & SD & Range & $\mathbf{N}$ & $\%$ \\
\hline Age & 39.7 & 11 & $18-64$ & & \\
\hline Gender & & & & & \\
\hline Male & & & & 91 & 73.4 \\
\hline Female & & & & 33 & 26.6 \\
\hline Marital status & & & & & \\
\hline Single & & & & 97 & 78.2 \\
\hline Married & & & & 23 & 18.5 \\
\hline Divorced & & & & 2 & 1.6 \\
\hline Widowed & & & & 2 & 1.6 \\
\hline Education & & & & & \\
\hline None & & & & 5 & 4.1 \\
\hline Primary & & & & 7 & 5.6 \\
\hline Secondary & & & & 48 & 38.7 \\
\hline Professional & & & & 64 & 51.6 \\
\hline Employment & & & & & \\
\hline Employed & & & & 86 & 69.4 \\
\hline Unemployed & & & & 19 & 15.3 \\
\hline Home & & & & 11 & 8.9 \\
\hline Student & & & & 6 & 4.8 \\
\hline Other & & & & 2 & 1.6 \\
\hline
\end{tabular}


Table 2. Descriptive statistics and correlations between variables $(n=124)$.

\begin{tabular}{|l|l|l|l|l|l|l|l|l|}
\hline & $\mathbf{M}$ & $\mathbf{S D}$ & $\mathbf{M i n}-\mathbf{M a x}$ & $\mathbf{1}$ & $\mathbf{2}$ & $\mathbf{3}$ & $\mathbf{4}$ & $\mathbf{5}$ \\
\hline 1. Adherence behaviors & 4.9 & 0.2 & $1-5$ & & & & & \\
\hline 2. Past competencies & 17.1 & 3.5 & $4-20$ & 0.05 & & & & \\
\hline 3. Current competencies & 22.1 & 3.3 & $5-25$ & $0.19^{* *}$ & 0.05 & & & \\
\hline 4. Motives & 14.6 & 1.9 & $5-16$ & 0.05 & 0.07 & 0.05 & & \\
\hline 5. Alcohol use & 1.3 & 0.9 & $1-5$ & -0.08 & -0.05 & $-0.58^{* *}$ & 0.03 & \\
\hline 6. Drugs use & 1.5 & 1.1 & $1-5$ & 0.01 & 0.03 & $-0.59^{* *}$ & -0.05 & $0.65^{* *}$ \\
\hline
\end{tabular}

$$
{ }^{*} p<0.05 ;{ }^{* *} p<0.01 \text {. }
$$

Figure 2. Standardized parameter estimates of the final model: $\chi^{2} / \mathrm{gl}=1.42, \mathrm{GFI}=0.99, \mathrm{AGFI}=0.94, \mathrm{NFI}=0.98, \mathrm{CFI}=$ $0.99, \mathrm{FD}=0.02[\mathrm{FDMI}=1.13], \mathrm{PNCP}=0.01[\mathrm{PNCPMI}=1.08], \mathrm{RMSEA}=0.05, \mathrm{RMSSR}=0.04$.

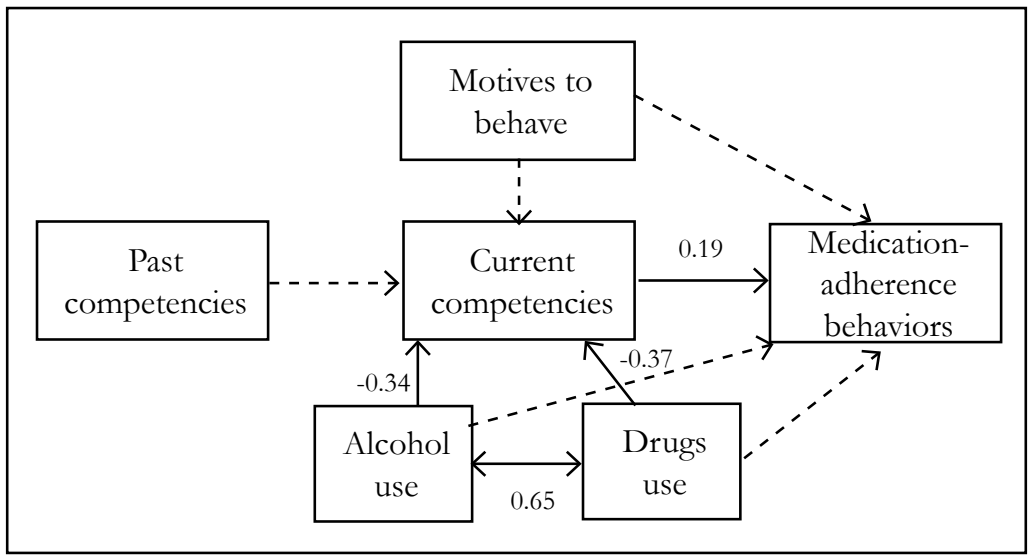

current behavioral competencies, as well as a low alcohol and drugs use. The behavioral competencies is a key factor in the $\mathrm{PMAB}$ and includes the knowledge, abilities and skills that are expected HIV+ persons implement to deal with the disease and the requirements derived from the different ART regimens. For the purpose of this study, we took into account questions regarding the follow up of the instructions provided by the health team, the adjustment to potentially negative situation - those generating a transitory or permanent state of stress or depression, mainly, as well as those implicated in the maintenance of interpersonal relationships with family and other significant persons of their close social environment.

Based on this type of questions, we found that participants evidenced a good level of behavioral competencies and, therefore, these ones facilitated in a direct way the practice of medication-adherence behaviors. This result is coincident with the reported in the PMAB for HIV+ persons 100\% adherents in Mexico [21, 22]. Furthermore, it is necessary to notice the important role played by the low use of substances like alcohol and drugs, which were related in a direct way with the behavioral competencies performance, this ones mediating their influence on medication-adherence behaviors. In an opposite direction to the reported on studies recently conducted around the world [2325], for this sample it is evidenced a low use of both substances, whose average were 1.34 for the use of alcohol and 1.55 for the use of drugs.

On the other hand, particularly interesting on this study was the observed relation between the behavioral competencies factor and the substance use. This last has showed that it can affect in a direct way the competencies performance, the abilities or the self-efficiency to practice medication-adherence behaviors, with potentially negative effects on health indicators, e.g., the lymphocytes $\mathrm{CD}^{+}{ }^{+}$counts, and the levels of viral load [26-28]. Because substances use were measured with an index that puts emphasis on his use in the lapse of the last 30 days, these behaviors must be understood as a variable of contextual nature, interacting with other of accumulative nature and continually modifiable, e.g., behavioral competencies and motives. Thus, from a psychological perspective it is necessary to consider in the analysis the factors of the psychological history - e.g., personality, motives and past behavioral competencies - and those of the present context, to predict and understand why HIV+ persons consistently and efficiently practicing or not medication-adherence behaviors [2931].

Finally, in this study it is necessary to recognize several limitations. At first, we carried out a cross-sectional study including a sample of $124 \mathrm{HIV}+$ persons from a state of Venezuela, and we can't generalize the results to other states of the country, where eventually deprive different healthcare conditions, the availability of resources and the access to different treatment regimens. Second, it is possible that an over-report of the medicationadherence behaviors and a low substance use exist, which in future studies will requires corroboration using other methods, such as the pill counts and pharmaceutical records. Third, the study was conducted in a specialized attention clinic for persons with HIV/AIDS, which is facing economic problems, which it made it impossible to gather detailed and updated information of the main biomarkers, the lymphocytes $\mathrm{CD}^{+}$counts and the levels of viral load. 
Once this limitations are been pointed out, understanding that this is the first study that takes place in that country based on a psychological model, we considered it that the findings here reported open an interesting window of opportunities to delve a line of investigation in the different clinics that take care of the HIV+ persons of Venezuela, with the main objective to contribute with the health authorities of the country in the design, instrumentation and evaluation of behavioral intervention programs related to ART adherence. It is about to seek a better use of the human, material and technological resources that are available in a developing country, according to the recommendations expose for other authors $[32,33]$.

\section{References}

[1]. Ironson GH, O'Cleirigh C, Schneiderman N, Weiss A, Costa PT (2008) Personality and HIV disease progression: Role of NEO-PI-R openness, extraversion, and profiles of engagement. Psychosom Med 70(2): 245-253.

[2]. Oser ML, Trafton JA, Lejuez CW, Bonn-Miller MO (2013) Differential associations between perceived and objective measurement of distress tolerance in relation to antiretroviral treatment adherence and response among HIVpositive individuals. Behav Ther 44(3): 432-442.

[3]. Sánchez-Sosa JJ, Ybarra JL, Piña JA (2012) A psychological model for adherence behavior among HIV-positive persons: Research and perspectives. Int J Hisp Psychol 5(2): 135-150.

[4]. Gordillo V, Fekete EM, Platteau T, Antoni MH, Schneiderman N, et al., (2009) Emotional support and gender in people living with HIV: effects on psychological well-being. J Behav Med 32(6): 523-531.

[5]. Safren SA, Biello KB, Smeaton L, Mimiaga MJ, Walawander A, et al., (2014) Psychosocial predictors of non-adherence and treatment failure in a largescale multi-national trial of antiretroviral therapy for HIV: Data from the ACTG A5175/Pearls Trial. PLoS One 9(8): e104178.

[6]. Newman MG, Schneider M, Nanau RM, Parry Ch (2012) Alcohol consumption, progression of disease and other comorbidities, and response to antiretroviral medication in people living with HIV. AIDS Res Treat. 14. Article ID 751827.

[7]. Jones D, Cook R, Cecchini D, Sued O, Bofill L, et al., (2015) Examining adherence among challenging patients in public and private HIV care in Argentina. AIDS Behav 19(9): 1619-1629.

[8]. Varela M, Galdames S (2014) Depression and HAART adherence in HIV infected patients attending Hospital San Pablo of Coquimbo, Chile [In Spanish]. Rev Chil Infectol 31(3): 323-328.

[9]. Pacífico J, Gutiérrez C (2015) Information about the medicines and adherence to highly active antiretroviral treatment in patients with HIV/AIDS in a hospital of Lima, Peru [In Spanish]. Rev Peru Med Exp Salud Publica 32(1): 66-72.

[10]. Harris J, Pillinger M, Fromstein, D, Gómez B, Garris I, et al., (2011) Risk factors for medication non-adherence in HIV infected population in the Dominican Republic. AIDS Behav 15(7): 1410-1415.

[11]. Bastardo YM, Kimberlin CL (2000) Relationship between quality of life, social support and disease-related factors in HIV-infected persons in Venezuela. AIDS Care 12(5): 673-684.

[12]. Bastardo YM, Castro JS, Suárez JA, Torres JR, Comegna M, et al., (2013) Adherence to antiretroviral therapy among HIV-infected patients attending to a university infectious diseases clinic in Venezuela (PIN 116). Value Health 16(7): A361.

[13]. Piña JA, Sánchez-Sosa JJ (2007) Psychological model for the research of adherence behaviors in persons with HIV [In Spanish]. Univer Psychol 6(2): 399-407.

[14]. Piña JA, González MT (2010) A psychological model of adherence among HIV+ persons: Structural equation modeling [In Spanish]. Rev Iberoam Psicol Salud 1(2): 185- 206.

[15]. González MT, Piña JA (2011) Motives, social support, and adherence behav- iors in HIV- positive patients: Structural equation modeling. [In Spanish]. Univer Psychol 10(2): 399-407.

[16]. Rosas MA, González MT (2012) Social support and motives: Their influence on treatment adherence and biomarkers among HIV patients from Michoacan, Mexico. Int J Hisp Psychol 5(2):167-180.

[17]. Piña JA, Corrales AE, Mungaray K, Valencia MA (2006) Instrument for measuring psychological variables and adherence to treatment behavior in persons who are seropositive for HIV (VPAD-24) [In Spanish]. Rev Panam Salud Publica 19(4): 217-228.

[18]. Álvarez EM, González RD, Miaja M, Piña JA, Fierros LE (2015) Validation of a simplified questionnaire measuring psychological variables and medication-adherence behaviors among HIV-positive persons from Venezuela. Rev Latinoam Med Cond 5(1):1-8.

[19]. Byrne BM (2001) Structural equation modeling with AMOS, EQS, and LISREL: Comparative approaches to testing the factorial validity of a measuring instrument. Int J Testing 1(1): 55-86.

[20]. Kline RB (2010) Principles and practice of structural equation modeling (3rd edn). NewYork: The Gilford Press.

[21]. Sánchez-Sosa JJ, Fierros LE, Cázares O, Piña JA (2011) Longitudinal study of psychological variables and adherence behaviors in HIV+ persons: effects on viral load [In Spanish]. Disorders and chronic diseases: A psychological approach.Autonomous University of Tamaulipas / The Modern Manual, México. 137-154.

[22]. Piña JA, García-Cadena CH, Ybarra JL, Fierros LE (2012) Psychological and biological variables among HIV 100\% adherent patients: A path analysis. In: García-Cadena CH, Ballester R, Piña JA, editors. Chronic diseases and medication adherence behaviors: Psychological research in Ibero-American countries. Hauppauge NY: Nova Science Publishers.203-219.

[23]. Pellowski JA, Kalichman SC, Kalichman MO, Chauncey C (2016) Alcoholantiretroviral therapy interaction toxicity beliefs and daily medication adherence and alcohol use among people living with HIV. AIDS Care 28(8): 963-970.

[24]. Tran BX, Nguyen N, Ohinmaa A, Duong AT, Nguyen LT, et al., (2013) Prevalence and correlates of alcohol use disorders during antiretroviral treatment injection-driven HIV epidemics in Vietnam. Drug Alcohol Depend 127(1-3): 39-44

[25]. Blashill AJ, Bedeoya CA, Mayer KH, O'Cleirigh C, Pinkston MM, et al., (2015) Psychosocial syndemics are additively associated with worse ART adherence in HIV-infected individuals. AIDS Behav 19(6): 981-986.

[26]. Parry CDH, Morojele NK, Myers BJ, Kekwaletswe CT, Manda SOM, et al., (2014) Efficacy of an alcohol-focused intervention for improving adherence to antiretroviral therapy (ART) and HIV outcomes - a randomized controlled trial protocol. BMC Infect Dis 14: 500 .

[27]. Camp M, Kahana SY, Altice FL (2012) A systematic review of antiretroviral adherence interventions for HIV-infected people who use drugs. Curr HIV/ AIDS Rep 9(4): 287-312.

[28]. Samet KH, Cheng DM, Libman H, Nunes DP, Alperen JK (2007) Alcohol consumption and HIV progression. J Acquir Immune Defic Synd 46(2): 194-199.

[29]. Oser ML, Trafton JA, Lejuez CW, Bonn-Miller MO (2013) Differential associations between perceived and objective measurement of distress tolerance in relation to antiretroviral treatment adherence and response among HIVpositive individuals. Behav Ther 44(3): 432-442.

[30]. O'Cleirigh C, Valentine SE, Pinkston M, Herman D, Bedoya CA, et al., (2015) The unique challenges facing HIV-positive patients who smoke cigarettes: HIV viremia, ART adherence, engagement in HIV care, and concurrent substance use. AIDS Behav 19(1): 178-185.

[31]. González MT, Ybarra JL, Piña JA (2012) Social relations, psychological variables and adherence behaviors in adults with HIV [In Spanish]. Int J Psychol Psychologic Ther 12(2): 173-184.

[32]. Simoni JM, Amico KR, Smith L, Nelson K (2010) Antiretroviral adherence interventions: Translating research findings to the real world clinic. Curr HIV/AIDS Rep 7(1): 44-51.

[33]. MacCarthy S, Hoffmann M, Ferguson L, Nunn A, Irvin R, et al., (2015) The HIV care cascade: models, measures and moving forward. J Int AIDS Soc18(1): 193-195. 